\title{
MOBILE PAYMENTS AND MAJOR SHIFTS IN CONSUMER BEHAVIOUR
}

\section{Claudiu Chiriac $^{1 *}$, Gheorghe Hurduzeu ${ }^{1}$, Andreea-Alexandra Chiriac (Roşca) ${ }^{2}$, loana-Coralia Zavera ${ }^{1}$}

${ }^{1}$ Faculty of International Business and Economics, The Bucharest University of Economic Studies, Bucharest, Romania

${ }^{2}$ Faculty of Marketing, The Bucharest University of Economic Studies, Bucharest, Romania chiriacclaudiu14@stud.ase.ro

gheorghe.hurduzeu@rei.ase.ro

r.andreea90@yahoo.com

zaveraioanacoralia@yahoo.com

\begin{abstract}
Considering the fact that in China, in 2016 solely, the mobile payment volume was around $\$ 5$ trillion - half of its gross domestic product, carried out through two main competitors - Alipay and Wechat Pay, it is becoming more and more clearer that companies will invest piles of money in order to process the payments of the millions of potential users. With banking industry shaken by the different modifications of rules and regulations and consumers addicted to latest gadgets, the tech companies may have the pole position in this race. Apple is charging each Apple Pay user with $0.15 \%$ per transaction which may not seem a lot, but taking into account that in 2015 iPhone users traded over $\$ 10.9$ billion we can see why tech companies are eager to develop payment applications. In this paper are presented briefly the newest means of payment and how are those influenced or not by the mainstream legislation. The most important piece in the gear - end-user - has to keep up with all the novelties in this sector and, as consequence, some behavioral patterns occur. Those are presented further in the text altogether with some trends in financial services that may influence the mobile payments market as we know it.
\end{abstract}

Keywords: payments, biometric, portal, web rooming

JEL classification: E42, O33, M31

\section{Tech companies and their initial undertakings}

Since 2007, Apple showed that it's a real trendsetter with respect to innovative solutions and that it has something to say when it comes to mobile devices. Taking into account job creation, research and development investment, product selling and last but not least the annual reports, the company proved to be a key player in the world's economic environment. Looking at the numbers, each and every year, when Q4 comes and the launching of a new iProduct is scheduled, the device's shipments are hiking. With every new product launch and new technology implementation, the company is driving the industry of portables in new directions and dimensions.

Starting with 2007, Apple Inc. led by its visionary Chief Executive Officer Steve Jobs, began to focus on developing portable devices. This was in his opinion an unexploited branch and he managed to improve it. Released in June, the original iPhone was 5 months away from the launching of one of the most coveted phone of that time - Nokia N95 8GB version. It had the specifications similar to Nokia N95 and with a $\$ 599$ price, it was even cheaper than the $\$ 749$ king of Symbian Operating System (Newsday Tribune, 2015). With thousands of mobile applications ready to be installed, Nokia had the first-mover advantage but also no

\footnotetext{
* Corresponding Author: Claudiu Chiriac
} 
records of its users. This was the main issue that killed a great operating system. With no feedback from the users, Nokia developed application just for the record and not for user's retention. Launched in 2008, Apple's proprietary App Store was the unique place where users could install tailor-made apps. It started with 500 apps but in May 2017 the total number of available apps reached 2.2 Bn. (The Daily Advertiser, 2013) (Costello, 2017). With the launch of the iPhone 2G (first generation iPhone), Apple also introduced to the masses the capacitive touchscreen, a different shift from the existent one at that time - the resistive touchscreen. It was a major improvement because in order to operate the phone you were not required to use a stylus anymore. Another premiere was the use of the SIM card tray. Unlike the existing phones in order to insert the SIM card in the phone, you had to eject the SIM tray, put the SIM card on it and then insert it back. Both concepts are standard in the industry 10 years after the launch of the first iPhone. Launched in 2010, with a mature technology onboard, the iPad followed a quite upward trend in sales and the company's cash growth increased from $\$ 11 \mathrm{Bn}$ to $\$ 39 \mathrm{Bn}$ (Bullish Cross, Philip Elmer-Dewitt). Innovative with some solutions, Apple is at the same time reserved when it comes to adopting hardware and software novelties. One example can be given by comparing the 2013 flagship phone of Samsung - Samsung S4 - released in April, with last flagship from Apple - iPhone X released in October 2017. It took 4 years and a half for Apple in order to implement wireless charging, compared to Samsung. It took also between 2 and 3 years compared to Google's Android Operating System to implement in their proprietary operating systems functions like notification center, personal hotspot etc.

\section{Mobile payments - present and future}

In 2013, with the launch of the iPhone 5S, Apple managed to shed the light first on mobile security and afterward on mobile payments. iPhone $5 \mathrm{~S}$ was the first iPhone with an embedded fingerprint reader named Touch ID. Originally showcased as a method of stopping unauthorized use of the phone, this laid the foundation of the Apple Pay platform. In a manner that Alan Curtis Kay (1992) pointed out - 'People who are serious about software should make their own hardware', Apple started to develop a hardware solution. Launched in late 2014, iPhone 6 together with iPhone 6+ were the first mobile phones to embed both software and hardware solution for mobile payments. Both phones came with Apple Pay software preinstalled and had implemented the entire hardware set for a secure payment: NFC - Near Field Communication antenna, fingerprint sensor and a microprocessor that encrypts the transactions. NFC is a wireless technology requiring $4-10 \mathrm{~cm}$ to initialize a connection between two mobile device; a standard that extends Radio Frequency Identification (RFID) by combining in one device the interface between a smartcard and a reader (Dospinescu, 2012).

Referring to ecosystems it is worth mentioning that older devices like iPhone 5, iPhone 5S and even old generation iPod touch can also use Apple Pay to make payments but only with the NFC chip embedded in Apple Watch. Basically having an Apple Watch enables a non-NFC capable Apple device to make payments via Apple's dedicated platform. The sole requirement for Apple Pay is to have a device with minimum the $8^{\text {th }}$ version of the Apple mobile operating system - iOS 8 - installed.

Unlike contactless cards, Apple Pay seals the payments covering a set of advantages. For example, when approving a payment, the software converts the card information into a hexadecimal code using the 'secure element' (Santus, 2014). This code can be read only by the point-of-sale. In case of security breach, the card details are safe because hackers can see only a hexadecimal code and not the name and surname of the owner, card number, CVC code etc. The equivalent of this mechanism implemented in the physical cards is 3D Secure, considered to be a high standard of safety of transactions on Internet (Dospinescu, 2012). 
According to a study published by PYMNTS.com, conducted in collaboration with InfoScout - a consumer research company - when it comes to mobile wallet adoption, Apple Pay is by far the most used for payments. In 32 months since launch, the usage has risen threefold compared to 2014 as presented in Figure 1.

This is strongly related to bank's adoption of the mobile payment. If in the case of mobile adoption, the increase was almost linear, the number of participating banks expanded from 20 in 2014 to approximately 2500 in 2017 - 304 in Asia-Pacific, 112 in Europe and the Middle East and 2000 in the United States and Canada (Apple, 2017).

With the launch of anniversary iPhone, Apple introduced on their stage another biometric sensor - face recognition - alias Face ID. Facial recognition technology has sparked controversy since its launch when Craig Federighi's face was not recognized when he tried to unlock the iPhone (Richardson, 2017). The main declared purpose of this technology is to improve the unlocking time of the iPhone and to make mobile payments run faster. As we speak, this technology is immature and no data can be analyzed since iPhone $X$ - the only iPhone with Face ID - is just starting to be rolled out in the stores.

Both Touch ID and Face ID technologies will be the pillars of Apple Pay Cash development. Implemented in the late version of iOS 11, Apple Pay Cash is a P2P - peer to peer service which enables users to wire the money via iMessage - Apple's proprietary messaging application. All transactions will be authorized via Touch ID or Face ID.

One might think that the fingerprint recognition and face recognition are the latest trends in the field. Actually, they are not. The implementation of fingerprint technology dates back in 2004 (Germain, 2004) and the topics related to facial recognition were discussed since 1966 by Woody Bledsoe (1966).

Another possible fallacy is to assume that Apple was the first company that introduced NFC payments. When Apple Pay was launched Nokia had implemented NFC for 10 years but only for interoperability among different devices (Microsoft Devices Team, 2012).

The main merit of Apple is not the implementation of biometric sensors in their technologies, or the using an apparent obsolete NFC technology after 10 years of failure. The main merit is that they managed to raise, to mature the software and then to integrate it with hardware, at the end developing a unique mobile payment ecosystem which inevitably induced competition among industry players (Zea et al., 2012).

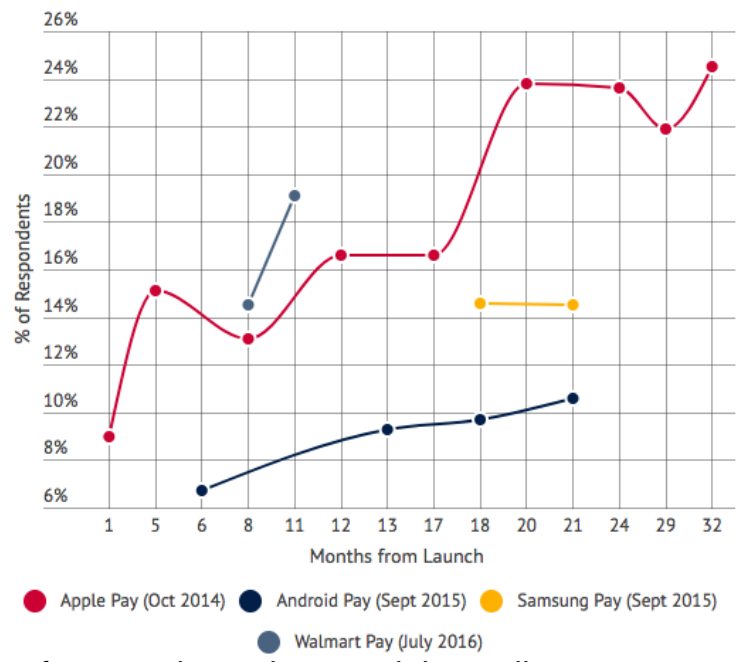

Figure 1: Percentage of respondents that used the wallet

Source: Webster, 2017 


\section{Major shifts in consumer behaviour}

The evolution of technology is also influencing consumer behavior and attitudes. The increasing number of the digitalized consumers is due to the fall of the price for technology; from 1999 to 2003, the computer price index has declined by 20\% each year (U.S. Department of Labor, 2015) and is steadily decreasing, allowing the entrance on the market of new consumers. Between 2016 and 2021, the number of internet users will increase with 4 billion, reaching a whopping 6.1 billion high-speed data connections (Cisco, 2017). Moreover, $75 \%$ percent of the 8.5 billion people - the population estimation by 2030 - will have smartphone and internet access (Benson-Armer, et al., 2015). In the same time, the consumer's sophistication is also growing, the technology being perceived by consumers as beneficial, hence computers, mobile phones, digital cameras and the internet being considered factors that improve the quality of life (Hoyer \& Maclnnis, 2008, p. 364). This phenomenon of technology adoption is even more accelerated among younger generations who are highly connected. About $56 \%$ of millennials use two or more electronic devices daily in the United States, such as cell phones and the Internet (Hawkins \& Mothersbaugh, 2016, p. 61).

The penetration of high-speed internet has brought significant changes of the online consumers and also changed the marketing and the research methods of the consumer. When it comes about the shopping, the consumers have a large gamut of options, because they can shop in the store, on the phone or on the internet. A study conducted in 2016 by Price Waterhouse Coopers shows that more than half of the online buyers are weekly or monthly online shoppers (2016). Not only that online shopping has sky-rocketed, but the consumer is currently shopping and choosing from a larger variety of products compared to the beginnings of the Internet. However, there are products with a higher associated risk for shopping via the internet, such as furniture, building materials etc. For this niche of products, the consumer uses the internet solely for information, preferring to shop in the traditional brick and mortar shop (Hoyer \& Maclnnis, 2008, p. 208).

In this new digital environment, the consumers constantly move from one channel to another, from online to offline and vice versa. In this context, two new purchase scenarios are common in the digital area: showrooming and webrooming. First scenario refers to customer journey which starts with visits in the traditional stores, but the product is bought online for a better price. The second scenario starts with learning about a product from online ads or social media. After the consumer decided which products are suitable for him, the purchase will be made in store (Kotler \& Keller, 2016).

Taking into account the integration of multiple channels, the payment is the last step in creating this seamless customer journey adapted to a nowadays digitalized consumer. Because the consumer has many options, the mobile payments should distinguish from the others, emphasizing the benefits they have like speed, ergonomics, convenience and mainly security - one of the most important criterion. The incentives altogether with other additional services can help the adoption of a certain type of mobile payment. For example, the developers may include an integrated system with discounts and loyalty programs for certain stores (Beutin \& Dagmar, 2017).

New payment methods are emerging, as seen in Figure 2, mainly because nowadays digital commerce is no longer limited to smartphones, computers, and tablets. All the devices incorporated with sensors like home appliances, smart homes, smart locks, wearables and so on so forth have a great potential to bring changes in the current commerce but also in the payment system. Consumers are also switching from texting to voice commands, personal virtual assistants like Amazon's Alexa, Siri, Google Now and Cortana being more and more common when it comes to online shopping (Evans, 2017). It was even a mainstream joke when Jeff Bezos - the CEO of Amazon - bought the Whole Foods Market saying that he has bought it by mistake; he just wanted something from Whole Foods and ordered through his 
personal virtual assistant. Alexa misunderstood the command and has bought the entire company.

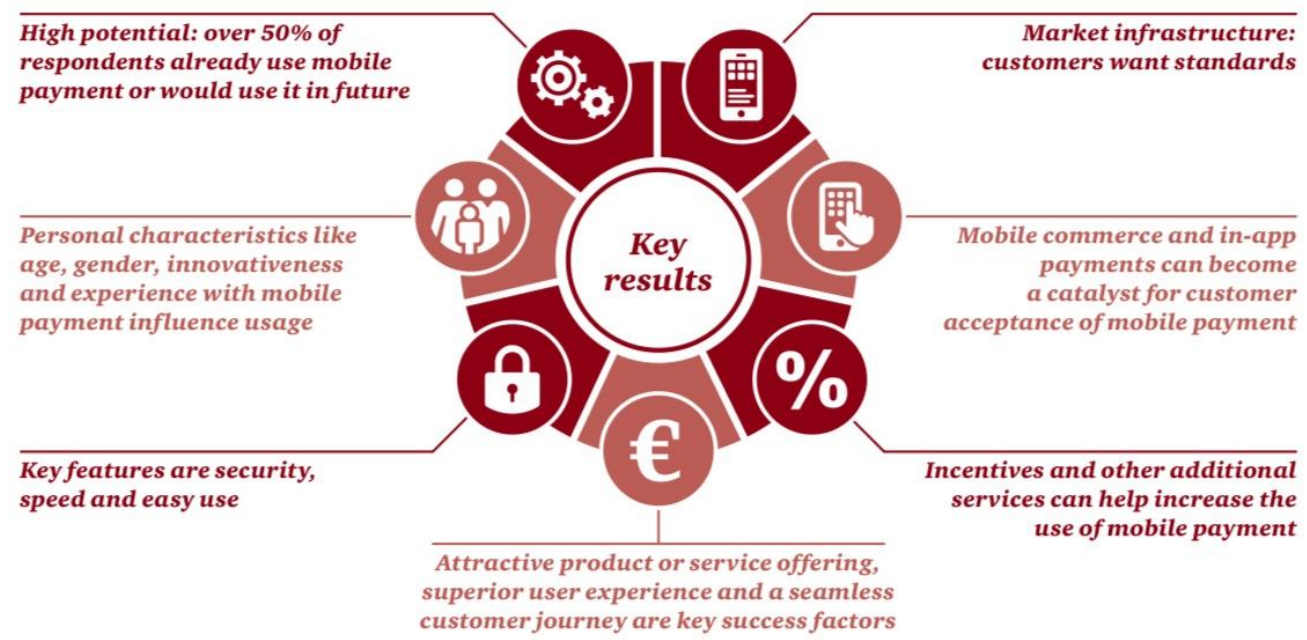

Figure 2: Mobile payment trends

Source: Nicolas \& Dagmar, 2017, p.7

\section{Legislative changes in mobile payments market}

In 2007 the European Parliament adopted the Payment Services Directive (PSD) a directive meant to help Single Euro Payments Area (SEPA) by increasing the transparency in transactions and lowering the fees. In 2015, the second PSD was adopted. PSD2 will be in force at national level starting with 2018 and will bring disruptive regulation for the mobile payments market. With the advance permission of the client, retailers will be able to use the bank details of consumers for processing the payments without third-parties; it will be a direct connection between banks and retailers, enabled with Application Programming Interface (API).

The information about the bank accounts will be at the fingertips of the so-called Account Information Service Provider (AISP) which will allow the multi-bank client to see the information from all bank accounts in one aggregated portal (Ramburs, 2017).

All these changes are made to better protect the consumer against fraud and ban the additional costs for payments, hence the companies must ensure the highest levels of security in order to meet the legislative criteria (Jerram, 2017).

Another regulation created by the European Union is General Data Protection Regulation which has the purpose of enhancing the privacy of EU citizens. Payments involve a lot of sensitive personal information about clients and it is imperative for the mobile payments providers to protect the related data (Aisien, 2017).

\section{Other trends in financial services}

Technology influences the disruption on financial services market. In this regard, there are some trends that will influence this industry, mobile payments market included.

a. Fintech companies are disruptive forces, usually start-ups companies, which innovate an element in the financial services chain. 
b. The sharing trends revealed in other industries, like automotive and accommodation may enter also in this industry. The sharing economy will be enabled by information technology and will connect the capital providers with the capital users.

c. Blockchain and cryptocurrency

d. Digital is no longer a novelty in the market, it becomes mainstream. The focus now is on big data analysis.

e. The data about consumers' needs and wishes are no longer just based on what consumers declare, now the technology gives access to more in-depth information about what consumers want (e.g. analyzing the consumer's online conversations).

f. The advances in technology and artificial intelligence will replace the interaction with a bank consultant with highly-skilled robots with the ability to learn and share the information with other robots.

g. The main infrastructure will be the public cloud as many financial companies use cloud-based software-as-a-service applications for business processes.

h. The cyber-security is one of the main risks for financial companies.

i. Asia will be the key center of technology-driven innovation.

j. The regulators will use technology to better monitor and predict potential problems for creating adapted regulations (PWC, 2017).

\section{Conclusions}

If in the first part it was presented the manner in which the giant players from high-tech industry influenced and continues to influence mobile payments industry, in the second part the focus was on the consumer because it is a reciprocal bond. Not only the end-user has to keep up with technology but also the technology providers should be aware of the users' needs. In order to have implemented a successful mobile payment platform, high-tech companies and banks must work together in order to provide quality services with respect to legislation. It is not enough to bring something new in the market taking into account that users tend to migrate to platforms that are simplifying processes. For this Apple is being highly criticized for the implementation of the controversial Face ID and dropping of the much faster Touch ID payment method in the newest iPhone.

The main takeaway of this paper is that although the mobile payments industry is exponentially growing, is also very volatile, and it is directly influenced by the big tech companies. At least at EU level, once the legislation which made the speech will enter into force the banking sector has to make serious investments in order to stay competitive.

\section{Acknowledgements}

This research paper was carried out with no dedicated funding.

\section{References}

Aisien, J., 2017. The Impact of GDPR On Today's Mobile Enterprise. [Online] Available at: https://www.scmagazine.com/the-impact-of-gdpr-on-todays-mobile-enterprise/article/71001 9/ [Accessed 4 January 2018].

Apple, 2017. Apple Pay participating banks and card issuers. [Online] Available at: https://support.apple.com/en-us/ht206638 [Accessed 31 October 2017].

Benson-Armer, R., Steve , N. and Alexander , T., 2015. The consumer sector in 2030: Trends and questions to consider. [Online] Available at: https://www.mckinsey.com/industries/consumer-packaged-goods/our-insights/the-consume r-sector-in-2030-trends-and-questions-to-consider [Accessed 20 December 2017]. 
Beutin, N. and Dagmar, S., 2017. Mobile Payment Report 2017, Düsseldorf: PricewaterhouseCoopers $\mathrm{GmbH}$.

Bledsoe, W., 1966. The Model Method in Facial Recognition. Technical Report PRI-15, California: Panoramic Research Inc..

Cisco, 2017. Cisco Visual Networking Index: Global Mobile Data Traffic Forecast Update, 2016-2021. [Online] Available at: https://www.cisco.com/c/en/us/solutions/collateral/service-provider/visual-networking-index -vni/mobile-white-paper-c11-520862.pdf [Accessed 4 January 2018].

Costello, S., $2017 . \quad$ Lifewire. [Online] Available at: https://www.lifewire.com/how-many-apps-in-app-store-2000252 [Accessed 30 October 2017].

Dospinescu, O., 2012. E-Wallet. A New Technical Approach. Acta Universitatis Danubius: Oeconomica, 8(5), pp. 84-94.

Dospinescu, O., 2012. Mobile payments. From mobility to security. The Young Economists Journal, 12 November, Issue 19, pp. 190-193.

Evans, M., 2017. Three Payment Trends That Will Change How We Pay in 2018. [Online] Available

at: https://www.forbes.com/sites/michelleevans1/2017/10/27/three-payment-trends-that-will-ch ange-how-we-pay-in-2018/\#37bc90476c2c [Accessed 6 January 2018].

Germain, J., 2004. IBM Introducing Fingerprint Reader into Laptop. [Online] Available at: https://www.technewsworld.com/story/37017.html [Accessed 9 December 2017]

Hawkins, D. I. \& Mothersbaugh, D. L., 2016. Consumer behavior : building marketing strategy. Thirteenth edition ed. New York: McGraw-Hill Education.

Hoyer, W. D. \& MacInnis, D. J., 2008. Consumer Behavior. 5th edition, revised ed. s.l.:Cengage Learning.

Jerram, P., 2017. PSD2 and securing mobile payments. [Online] Available at: https://www.linkedin.com/pulse/psd2-securing-mobile-payments-paul-jerram [Accessed 8 December 2017].

Kay, A. C., 1982. Creative Think Seminar.

Kotler, P. T. \& Keller, K. L., 2016. Marketing Management. 15th edition ed. s.l.:Pearson.

Newsday Tribune, 2015. Tech Extra, Dayton, Ohio: CMG Corporate Services, Inc. on behalf of itself and the Newspapers.

Nicolas, B. \& Dagmar, S., 2017. Mobile Payment Report 2017 What customers really want. [Online] Available at:

https://www.pwc.de/de/digitale-transformation/studie-mobile-payment-report-2017.pdf

[Accessed 14 December 2017].

PWC, 2017. Financial Services Technology 2020 and Beyond: Embracing disruption. [Online] Available at: https://www.pwc.com/gx/en/industries/financial-services/publications/financial-services-tec hnology-2020-and-beyond-embracing-disruption.html [Accessed 8 January 2018].

Ramburs, 2017. Let's talk about PSD2 and mobile payments. [Online] Available at: https://www.rambus.com/blogs/lets-talk-about-psd2-and-mobile-payments/ [Accessed 5 December 2017].

Richardson, S., 2017. Apple's Failed Facial Recognition Demo Generates Criticisms, Arkansas: Uloop, Inc..

Santus, R., 2014. Why Apple Pay Is the Most Secure Payment Platform on the Planet. [Online] Available at: http://mashable.com/2014/10/23/apple-pay-is-more-secure-than-your-credit-and-debit-card s/\#KKrboptzdugw [Accessed 24 October 2017].

Team, M. D., 2012. Nokia's NFC phone history. [Online] Available at: https://blogs.windows.com/devices/2012/04/11/nokias-nfc-phone-history/\#OG88i8obFKFc PYoj.97 [Accessed 1 November 2017]. 
The Daily Advertiser, 2013. Lafayette: Gannett Co., Inc..

U.S. Department of Labor, 2015. Long-term price trends for computers, TVs, and related items.

[Online]

Available

at:

https://www.bls.gov/opub/ted/2015/long-term-price-trends-for-computers-tvs-and-related-it ems.htm [Accessed 28 January 2018].

Webster, B., 2017. What Walmart Pay Knows That Apple Pay Doesn't. [Online] Available at: https://www.pymnts.com/news/payments-innovation/2017/apple-pay-mobile-wallet-adoptio n-usage-stats/ [Accessed 18 December 2017].

Zea, O. M., Dominik, L., Andrew, S. and Lars, H., 2012. Understanding the current state of the NFC payment ecosystem: A graphbased analysis of market players and their relations. Enfoque, 3 (2), pp. 13-32.

\section{Bio-note}

Chiriac Claudiu is a Ph.D. student in the The Bucharest University of Economic Studies Economics and International Affairs Program. As Ph.D. student, Claudiu is focused on studying the mobile payment industry and what are the implications of this industry in the global financial environment.

Hurduzeu Gheorghe, Prof. Phd., is the dean of the Faculty of International Business and Economics within The Bucharest University of Economic Studies.

Chiriac (Roșca) Andreea-Alexandra is a Ph.D. student in the The Bucharest University of Economic Studies - Marketing Program. As Ph.D. student, Andreea is focused on studying innovative methods and marketing research techniques applied to the modern consumer.

Zavera loana-Coralia is a Ph.D. student in the The Bucharest University of Economic Studies - Economics and International Affairs Program. As Ph.D. student, Coralia is focused on optimizing welfare redistribution processes in EU member states. 